\title{
High expression of RAB38 promotes malignant progression of pancreatic cancer
}

\author{
BAO-YU LI, LI-JIE HE, XIANG-LIAN ZHANG, HUI LIU and BIN LIU \\ Department of General Surgery, The Secondary Hospital of Tianjin Medical University, Tianjin 300211, P.R. China
}

Received March 23, 2018; Accepted November 5, 2018

DOI: $10.3892 / \mathrm{mmr} .2018 .9732$

\begin{abstract}
Ras-Related Protein Rab-38 (RAB38), which belongs to the RAB family, is involved in the biogenesis of lysosome-related organelles and defense against certain microbial infections. However, the clinical significance and potential function of RAB38 in pancreatic adenocarcinoma remain unclear. In the present study, an immunohistochemical assay was performed to analyze the expression of RAB38 in pancreatic adenocarcinoma tumor specimens from 82 patients, and the clinicopathological characteristics and survival rate of these patients were further examined. To validate the role of RAB38 in tumors, the effect of RAB38 on tumor cell proliferation, migration and invasion was assessed by establishing RAB38 knockdown cell lines. Reverse transcription-quantitative polymerase chain reaction and western blotting were used to examine the expression levels of proteins associated with the cancer cell behavior. In addition, the inhibitory effect of RAB38 silencing on pancreatic cancer was examined in mice. The immunohistochemistry results revealed that RAB38 was upregulated and positively correlated with the grade of progression in pancreatic adenocarcinoma patients. Further investigation indicated that RAB38 downregulation significantly suppressed the proliferation, migration and invasive capacity of pancreatic cancer cells, as well as decreased the expression levels of Ki67, proliferating cell nuclear antigen, and matrix metalloproteinases 2 and 9. RAB38 silencing also inhibited the development of pancreatic cancer in vivo. Taken together, a high level of RAB38 was significantly associated with the malignant phenotypes of pancreatic cancer, suggesting that RAB38 may serve as a novel biomarker and a potential therapeutic target for pancreatic cancer.
\end{abstract}

Correspondence to: $\mathrm{Dr}$ Bao-Yu Li, Department of General Surgery, The Secondary Hospital of Tianjin Medical University, 23 Pingjiang Road, Hexi, Tianjin 300211, P.R. China

E-mail: wkbfhlj@163.com

Key words: RAB38, clinicopathological characteristics, pancreatic cancer, RNA interference, in vitro, in vivo

\section{Introduction}

Pancreatic cancer is a commonly diagnosed cancer and one of the main causes of cancer-associated mortality $(1,2)$. The incidence of pancreatic cancer increases yearly, and $95 \%$ of pancreatic cancer cases involve adenocarcinomas (3-5). It is reported that the 5-year survival rate of pancreatic cancer patients is only $20 \%$ following surgical resection, chemotherapy and radiation treatment $(6,7)$. The majority of patients are diagnosed at a late stage with regional invasion or distant metastasis, due to the lack of recognizable clinical symptoms or signs (8-10). Therefore, it is urgent to screen effective biomarkers for the prediction of tumor progression.

Ras-Related Protein Rab-38 (RAB38) is a member of the RAB small G protein family (11), which is involved in regulating signal transduction and cellular processes, including membrane trafficking, cell growth and differentiation (12-14). It is documented that the point mutations of RAB38 at the GTP binding domain can result in the Hermansky-Pudlak syndrome in humans (15-17). Previous studies reported that RAB38 was associated with the synthesis, storage and transport of melanin pigments in the biogenesis of melanosomes $(18,19)$. In addition, the RAB38 protein was overexpressed at the RNA level in melanoma cancer $(20,21)$. It has also been indicated that the high expression of RAB38 increased the progression of gliomas, and was associated with poorer prognosis (17). However, the clinical significance and potential function of RAB38 in the progression of pancreatic cancer remain unclear.

In the present study, the RAB38 expression level was analyzed in pancreatic cancer specimens from 82 patients, and its correlation with the clinicopathological characteristics and survival rate of these patients was examined. The study then established RAB38 knockdown PANC-1 and BxPC-3 cell lines by RNA interference (RNAi) technology, followed by assessing the effect of RAB38 silencing on the proliferation, migration and invasion of pancreatic cancer cells. In addition, the effect of low RAB38 expression was further investigated in PANC-1 xenograft tumor-bearing mice.

\section{Materials and methods}

Specimen collection and ethics statement. Procedures involving human samples and animals used in the present study were approved by the Ethics Committee of the Secondary Hospital of Tianjin Medical University (Tianjin, China). Written informed 
consent was provided by all the participants of the present study. Subsequent to obtaining the Institutional Review Board approval, the current study identified 82 patients undergoing standard radical resection of pancreatic cancer in the Secondary Hospital of Tianjin Medical University between March 2012 and December 2015. All the patients had no history of preoperative radiotherapy, chemotherapy or neoadjuvant chemotherapy. All the patients did not manifest signs of tumor metastasis, as evidenced by cross-sectional imaging. Normal para-carcinoma tissues adjacent to carcinoma were obtained. All specimens were stored embedded in paraffin, at room temperature. The clinicopathological characters (such as age, sex, pTMN stage, tumor grade, tumor size, lymph metastasis, and vascular invasion) and outcome information of patient were recorded.

Immunohistochemical (IHC) analysis. IHC analysis was performed as described previously (22). Briefly, specimens were fixed in $4 \%$ paraformaldehyde, embedded in paraffin and cut into $4-\mu \mathrm{m}$ sections. Following deparaffinization and rehydration, the sections were subjected to antigen retrieval. Anti-RAB38 antibody (bs-11244R; BIOSS, Beijing, China) at $4^{\circ} \mathrm{C}$ overnight $(12 \mathrm{~h}$ ) was used to detect the RAB38 expression in the specimens and horseradish peroxidase (HRP; PV-6000; OriGene Technologies, Inc., Beijing, China)-labeled secondary antibody at room temperature for $20 \mathrm{~min}$. Color development was then performed by incubating with DAB provided in the kit (ZLI-9018; OriGene Technologies, Inc., Beijing, China), and the sections counterstained with $0.5 \%$ hematoxylin at room temperature for $20 \mathrm{sec}$ for cell nuclei and mounted. Images of the sections were subsequently captured with a light microscope (Olympus BX-51; Olympus Corporation, Tokyo, Japan).

All specimens were reviewed and scored by investigators blinded to the clinical characteristics of patients. The expression of RAB38 in tumor cells was scored as follows: 0, no positive expression in tumor cells; $1,<25 \%$ positive expression in tumor cells; $2,25-50 \%$ positive expression; and $3,>50 \%$ positive expression. The staining intensity was also determined according to the following scores: 0 (no staining), 1 (weak, light yellow staining), 2 (moderate, yellowish brown staining) and 3 (strong, brown staining). The staining index was calculated as follows: Staining index $=$ (staining intensity score) $\mathrm{x}$ (tumor cell staining grade). A staining index score of $\geq 4$ was defined as high RAB38 expression, while a staining index of $<4$ represented low expression of RAB38.

Cells and animals. PANC-1 and BxPC-3 human pancreatic adenocarcinoma cell lines were purchased from the American Type Culture Collection (Manassas, VA, USA). PANC-1 cells were cultured in Dulbecco's modified Eagle's medium, and BxPC-3 cells were cultured in Roswell Park Memorial Institute 1640 medium from The Cell Resource Center of Peking Union Medical College (Beijing, China). All cells were incubated in medium containing $10 \%$ fetal bovine serum and $1 \%$ penicillin combined with streptomycin at $37^{\circ} \mathrm{C}$ in $5 \% \mathrm{CO}_{2}$.

Female BALB/c nude mice ( $\mathrm{n}=30$; 6-8 weeks old; 20-25 g) were purchased from the Academy of Military Science (Beijing, China). The mice were maintained under a germ-free environment in individual ventilated cages, and at $20^{\circ} \mathrm{C}$, humidity 40-60\%, 12-h light/dark cycle and ad libitum access to standard lab chow and water.
Small hairpin RNA (shRNA) transfection. Pancreatic cancer cells were seeded in 6-well plates at a concentration of $3 \times 10^{4}$ cells/well and cultured overnight. The plasmid TRCN0000048183 and negative vector were purchased from Open Biosystems, Inc. (Huntsville, AL, USA) and designated as sh-RAB38 (23). Diluted shRNAs were added to Lipofectamine $^{\circledR} 2000$ (11668027; Thermo Fisher Scientific, Inc., Waltham, MA, USA) for $20 \mathrm{~min}$, and then the cells were transfected using the mixture and incubated at $4^{\circ} \mathrm{C}$ for $6 \mathrm{~h}$. Subsequently, the transfection effect was evaluated by reverse transcription-quantitative polymerase chain reaction (RT-qPCR) and western blot analysis.

$R T-q P C R$ assay. Total RNA in human cells was isolated by TRIzol reagent (Invitrogen; Thermo Fisher Scientific, Inc.). The OD260/OD280 of the RNA was 2.0. RNA was then reverse-transcribed into cDNA using PrimeScript RT Reagent kit (Takara Bio, Inc., Shiga, Japan). Next, qPCR was performed by Primer Mix Taq II (Takara Biotechnology Co., Ltd., Dalian, China) with the following conditions (24): $95^{\circ} \mathrm{C}$ for $2 \mathrm{~min}$ (1 cycle), $95^{\circ} \mathrm{C}$ for $5 \mathrm{sec}, 55^{\circ} \mathrm{C}$ for $30 \mathrm{sec}$, and $72^{\circ} \mathrm{C}$ for $30 \mathrm{sec}$ (35 cycles) and final extension at $72^{\circ} \mathrm{C}$ for $6 \mathrm{~min}$. Using the $2^{-\Delta \Delta \mathrm{Cq}}$ method (25), the relative expression level was normalized by the internal standard $\beta$-actin. The primer sequences used were: RAB38, 5'-GTAATCGGCGACCTAGGTG-3' (forward) and 5'-TCCATTCCCGGAACCTTCAC-3' (reverse); $\beta$-actin, 5'-CAGCTCACCATGGATGATGATATC-3' (forward) and 5'-AAGCCGGCCTTGCACAT-3' (reverse).

Western blot analysis. The nuclear and cytoplasmic protein was extracted by protein lysate, and the concentration of protein was measured by a protein assay kit (Beyotime Institute of Biotechnology, Haimen, China). Immunoblotting was then performed as previously described (6). Briefly, protein $(30 \mu \mathrm{g})$ was separated by $10 \%$ SDS-PAGE and transferred onto polyvinylidene difluoride membranes. The membranes were blocked by $1 \% \mathrm{BSA}$ at $4^{\circ} \mathrm{C}$ for $2 \mathrm{~h}$ and then incubated with appropriate primary antibodies at $4^{\circ} \mathrm{C}$ overnight, followed by incubation with secondary antibodies at $37^{\circ} \mathrm{C}$ for $2 \mathrm{~h}$. The primary antibodies used were as follows: Rabbit anti-RAB38 (1:400; bs-11244R; BIOSS), rabbit anti- $\beta$-actin (1:1,000; ab5694; Abcam, Cambridge, UK), rabbit anti-Ki67 (1:1,000; ab16667; Abcam), rabbit anti-proliferating cell nuclear antigen (PCNA; 1:500; ab18197; Abcam), rabbit anti-matrix metalloproteinase 2 (MMP2; 1:1,000; ab37150; Abcam) and rabbit anti-MMP9 (1:1,000; ab38898; Abcam). The secondary antibodies used in the assay were polyclonal goat anti-rabbit IgG antibodies (1:10,000; 711-1122; Rockland Immunochemicals, Inc., Limerick, PA, USA). Subsequently, the protein was visualized by Immobilon Western Chemiluminescent HRP Substrate (EMD Millipore, Billerica, MA, USA) and detected by Tanon-5500 Chemiluminescent Imaging System (Tanon Science \& Technology Co., Ltd., Shanghai, China). Western blot data were quantified by densitometric analysis with ImageJ software version LSM880 (National Institutes of Health, Bethesda, MD, USA), and the relative expression level was normalized by the internal standard $\beta$-actin.

Cell proliferation. Colony formation assays were used to test the proliferation ability of cells. Briefly, cells were seeded on 96-well plates at a concentration of 300 cells per well. The 
A
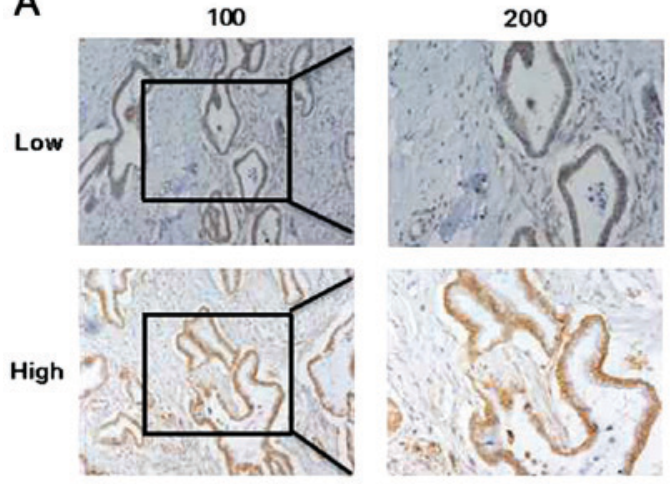

C

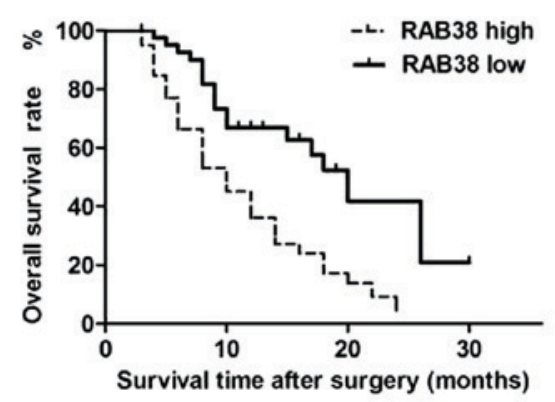

B
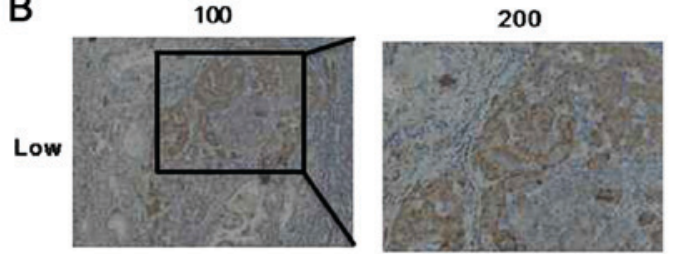

High
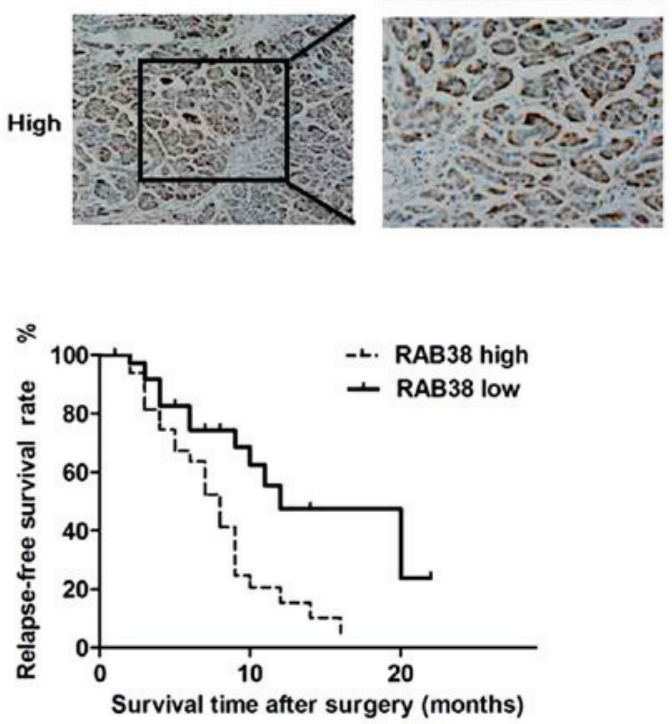

Figure 1. RAB38 expression is associated with the clinicopathological features of patients with pancreatic ductal adenocarcinoma. Representative immunohistochemical analysis images of RAB38 protein expression in (A) pancreatic ductal adenocarcinoma and (B) para-carcinoma tissues. (C) Association of OS and RFS rates with RAB38 expression in the 82 pancreatic cancer patients. Significantly shorter OS or RFS rates were observed in patients with high in comparison with low RAB38 expression $(\mathrm{P}<0.05)$. RAB38, Ras-related GTP-binding protein 38; OS, overall survival; RFS, relapse-free survival.

cells were fixed using methanol for $10 \mathrm{~min}$, and then the colonies were stained by crystal violet stain solution at room temperature (C0121; Beyotime Institute of Biotechnology) for 2 min and counted by an optical microscope.

MTT assay. Cells were grown for $12 \mathrm{~h}$ in $96-w e l l$ plates at a concentration of $5 \times 10^{3}$ cells/well. Next, $0.5 \mathrm{mg} / \mathrm{ml}$ MTT was added to the medium of each well and incubated for another $4 \mathrm{~h}$ at $37^{\circ} \mathrm{C}$. The supernatant was removed directly by pipettor and $100 \mu \mathrm{l}$ dimethyl sulfoxide was added. A microplate reader (EXL-800; BioTek Instruments, Inc., Winooski, VT, USA) was used to measure the absorbance at $570 \mathrm{~nm}$.

Scratch migration assays. The cells $\left(1 \times 10^{6}\right)$ were seeded on 6-well plates overnight. Next, a sterile pipette tip was used to introduce a scratch in the middle of the well. The migration of cells towards the center of the wound was measured at $48 \mathrm{~h}$.

Transwell invasion assay. A Transwell assay was conducted to assess the cell invasion ability in response to RAB38 silencing. The upper surface of the Transwell filter used in the assay was coated with Matrigel. Cells $\left(1 \times 10^{5}\right)$ suspended in $150 \mu \mathrm{l}$ serum-free medium were added to the Transwell chamber, which was then placed into a 24 -well plate containing complete medium. After $24 \mathrm{~h}$ of incubation at $37^{\circ} \mathrm{C}$, the filter was extracted, and Matrigel on the upper surface of the filter was removed by cotton swabs. Cells on the underside of the Transwell filter were then fixed with $4 \%$ paraformaldehyde for $25 \mathrm{~min}$ and stained with $0.1 \%$ crystal violet for $15 \mathrm{~min}$, following which images were captured and the result quantified by the number of cells.
Tumor challenge. The nude mice were divided into two groups $(\mathrm{n}=10)$, and then subcutaneously inoculated in the right groin with $1 \times 10^{6}$ PANC-1/control or PANC-1/sh-RAB38 cells, respectively. All mice were monitored daily, and tumor growth and body weight were measured on the days 14, 17, 21, 23, 26 and 29. The tumor size was calculated according to the following formula: Volume $=$ length $\mathrm{x}$ width $\mathrm{x}$ width/2.

Furthermore, in order to investigate the association between RAB38 and metastasis of pancreatic cancer cells, PANC-1 cells transfected with RAB38 shRNA and controls were used to establish the two kinds of stable cell lines, which were injected into the tail vein of mice, respectively. The metastatic lung tumors were detected and, after 4 weeks, the mice were euthanized and tumors were harvested.

Statistical analysis. The continuous variables data were presented as the mean \pm standard deviation. The Student's t-test for paired data was used to compare mean values. Categorical data were analyzed by the $\chi^{2}$ method. Statistical analyses were performed with IBM SPSS version 22.0 software (IBM Corporation, Armonk, NY, USA). P $<0.05$ was considered to denote a statistically significant difference.

\section{Results}

RAB38 protein expression is associated with clinicopathological features in patients with pancreatic cancer. A total of 82 pancreatic ductal adenocarcinoma (Fig. 1A) or para-carcinoma tissues (Fig. 1B) were used to detect the protein expression levels of RAB38 by IHC analysis. Positive RAB38 
Table I. Correlation of RAB38 with clinicopathological characteristics in 82 patients with pancreatic ductal adenocarcinoma.

\begin{tabular}{|c|c|c|c|c|c|}
\hline \multirow[b]{2}{*}{ Feature } & \multirow[b]{2}{*}{ No. } & \multicolumn{2}{|c|}{ RAB38 expression } & \multirow[b]{2}{*}{$\chi^{2}$} & \multirow[b]{2}{*}{ P-value } \\
\hline & & High $(n=40)$ & Low $(n=42)$ & & \\
\hline Age (years) & & & & 0.424 & 0.515 \\
\hline$<65$ & 64 & 30 & 34 & & \\
\hline$\geq 65$ & 18 & 10 & 8 & & \\
\hline Sex & & & & 0.402 & 0.526 \\
\hline Male & 48 & 22 & 26 & & \\
\hline Female & 34 & 18 & 16 & & \\
\hline pTNM stage & & & & 7.680 & $0.006^{\mathrm{a}}$ \\
\hline I & 24 & 6 & 18 & & \\
\hline II-III & 58 & 34 & 24 & & \\
\hline Tumor grade & & & & 4.767 & $0.029^{\mathrm{a}}$ \\
\hline Low & 62 & 26 & 36 & & \\
\hline High & 20 & 14 & 6 & & \\
\hline Tumor size (cm) & & & & 1.239 & 0.266 \\
\hline$<5$ & 58 & 26 & 32 & & \\
\hline$\geq 5$ & 24 & 14 & 10 & & \\
\hline Lymph node metastasis & & & & 2.656 & 0.103 \\
\hline No & 60 & 26 & 34 & & \\
\hline Yes & 22 & 14 & 8 & & \\
\hline Vascular invasion & & & & 4.091 & $0.043^{\mathrm{a}}$ \\
\hline No & 54 & 22 & 32 & & \\
\hline Yes & 28 & 18 & 10 & & \\
\hline
\end{tabular}

${ }^{a} \mathrm{P}<0.05$, indicating a statistically significant difference. RAB38, Ras-related GTP-binding protein 38 .

expression was detected in $48.8 \%(40 / 82)$ and $30.5 \%(25 / 82)$ of pancreatic ductal adenocarcinoma and para-carcinoma tissues. The positive rate in pancreatic ductal adenocarcinoma tissues was significantly higher in comparison with that in para-carcinoma tissues $\left(\chi^{2}=5.734 ; \mathrm{P}=0.017\right)$. The pancreatic ductal adenocarcinoma specimens included 40 samples with high RAB38 positive expression and 42 samples with low RAB38 positive expression (Fig. 1A).

To further evaluate the association between the expression of RAB38 and clinical outcome, the cancer relapse-free survival rate (RFS) and overall survival rate (OS) in patients according to their RAB38 expression was also examined. The results demonstrated that pancreatic ductal adenocarcinoma patients with high RAB38 expression exhibited a significantly shorter survival time as compared with those with low expression $(\mathrm{P}=0.042<0.05$ and $\mathrm{P}=0.046<0.05)$. Therefore, high RAB38 expression was significantly associated with much shorter RFS and OS in 82 patients with pancreatic ductal adenocarcinoma (Fig. 1C).

As shown in Table $\mathrm{I}$, the results indicated that the expression of RAB38 protein changed from low to high according to the grade progression of pancreatic ductal adenocarcinoma. Furthermore, high RAB38 expression was significantly associated with a higher pTNM stage, higher tumor grade and presence of vascular invasion. There were no significant association between RAB38 expression and other pathological factors, such as age, sex, tumor stage and lymph node metastasis (Table I). However, unlike pTNM stage or vascular invasion, RAB38 expression was not an independent clinical prognostic factor for pancreatic ductal adenocarcinoma (Table II).

ShRNA transfection of PANC-1 or BxPC-3 cells. To substantiate the role of RAB38 in pancreatic ductal adenocarcinoma, transfection with RAB38 shRNA was used to silence RAB38 in PANC-1 and BxPC-3 cells. Next, the RAB38 expression level was detected by RT-qPCR and western blot analysis in vitro. The results demonstrated that RAB38 expression in shRNA-transfected cells decreased significantly at the mRNA level as compared with that in the control cells. Furthermore, the expression of RAB38 proteins identified by western blot analysis was in accordance with the mRNA expression (Fig. 2). Therefore, RAB38 silencing in the cancer cells was successfully established by shRNA transfection.

RAB38 silencing suppresses the proliferation of cancer cells in vitro. The proliferation of tumor cells is important for tumorigenesis, while the proliferation of endothelial cells is a main factor influencing the tumor angiogenesis, which is associated with tumor development. Therefore, the current study evaluated the effects of RAB38 silencing on the proliferation of PANC-1 and BxPC-3 cells using colony formation 
Table II. Univariate and multivariate analyses of RFS and OS for RAB38 in pancreatic cancer.

\begin{tabular}{|c|c|c|c|c|c|c|c|c|}
\hline \multirow{3}{*}{$\begin{array}{l}\text { Clinicopathological } \\
\text { characteristic }\end{array}$} & \multicolumn{4}{|c|}{ RFS } & \multicolumn{4}{|c|}{ OS } \\
\hline & \multirow{2}{*}{$\begin{array}{l}\text { Univariate } \\
\text { P-value }\end{array}$} & \multicolumn{3}{|c|}{ Multivariate survival analysis } & \multirow{2}{*}{$\begin{array}{l}\text { Univariate } \\
\text { P-value }\end{array}$} & \multicolumn{3}{|c|}{ Multivariate survival analysis } \\
\hline & & $\mathrm{HR}$ & $95 \% \mathrm{CI}$ & P-value & & HR & $95 \% \mathrm{CI}$ & P-value \\
\hline Age & 0.292 & & & & 0.375 & & & \\
\hline Sex & 0.436 & & & & 0.528 & & & \\
\hline pTNM stage & 0.010 & 1.856 & $1.203-3.436$ & 0.047 & 0.014 & 1.895 & $1.005-3.574$ & 0.045 \\
\hline Tumor grade & 0.021 & 1.725 & $0.936-3.006$ & 0.080 & 0.026 & 1.659 & $0.860-3.118$ & 0.121 \\
\hline Tumor size & 0.319 & & & & 0.428 & & & \\
\hline Lymph node metastasis & 0.082 & & & & 0.113 & & & \\
\hline Vascular invasion & 0.011 & 1.845 & $1.335-3.605$ & 0.041 & 0.012 & 1.190 & $0.597-2.370$ & 0.044 \\
\hline RAB38 expression & 0.018 & 1.656 & $1.012-2.836$ & 0.069 & 0.014 & 0.676 & $0.322-1.255$ & 0.401 \\
\hline
\end{tabular}

RFS, relapse-free survival; OS, overall survival; HR, hazard ratio; 95\% CI, 95\% confidence interval; RAB38, Ras-related GTP-binding protein 38 .
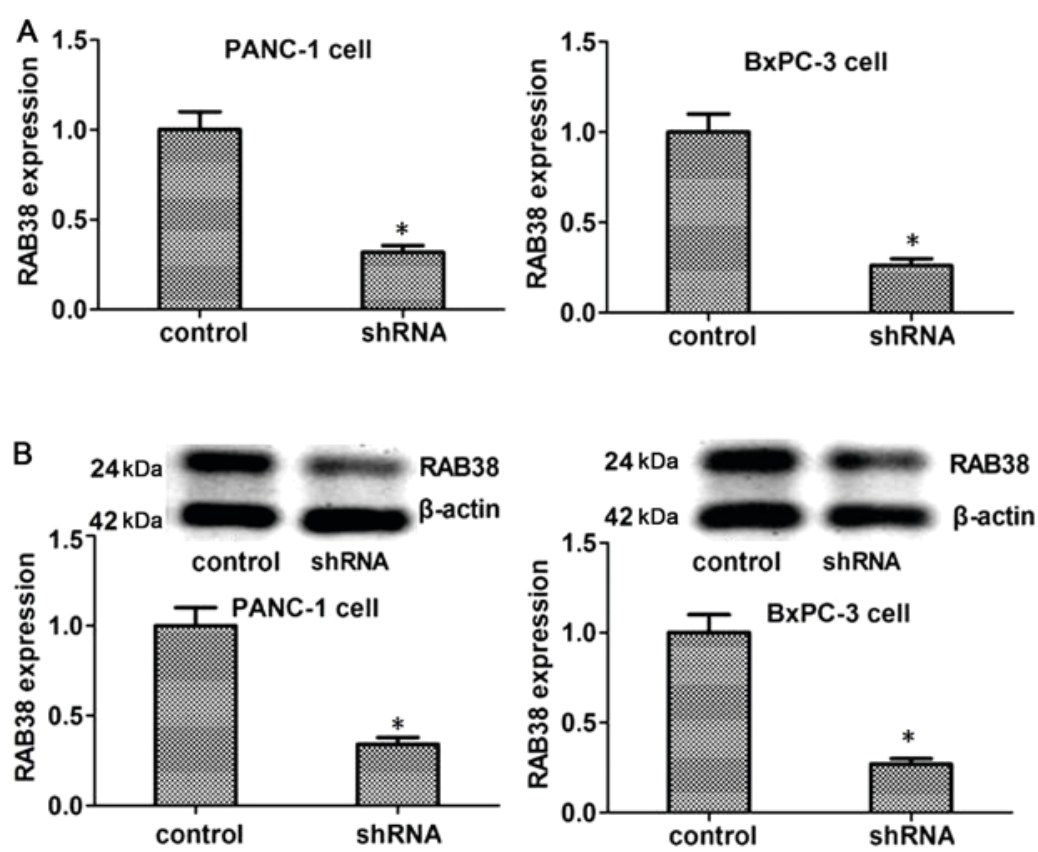

Figure 2. Effects of shRNA targeting of RAB38 in pancreatic cancer cell lines by lentivirus-based RNA interference transfection. (A) Reverse transcription-quantitative polymerase chain reaction and (B) western blot assay were used to examine RAB38 mRNA and protein expression, respectively, in PANC-1 and BxPC-3 cells transfected with RAB38 shRNA or negative control shRNA. Western blotting data were quantified by densitometric analysis with ImageJ software. Data are reported as the mean \pm standard deviation $(n=3)$. ${ }^{*} \mathrm{P}<0.05$ vs. control group. shRNA, small hairpin RNA; RAB38, Ras-related GTP-binding protein 38 .

and MTT assays. As shown in Fig. 3A and B, the results revealed that RAB38 silencing in PANC-1 and BxPC-3 cells suppressed their proliferation ability when compared with the control cells. To further explore the mechanism underlying this effect, the expression levels of Ki67 and PCNA were detected, which are proteins associated with proliferation. The results demonstrated that the expression levels of Ki67 and PCNA proteins decreased in the RAB38 shRNA-transfected group as compared with the control group (Fig. 3C and D). Taken together, these results suggested that RAB38 silencing was able to reduce cell proliferation by regulating associated proteins, such as Ki67 and PCNA, in vitro.
RAB38 silencing suppresses in vitro migration and invasion in PANC-1 and BxPC-3 cells. To further explore the roles of RAB38 in pancreatic cancer, the study investigated the effect of RAB38 on the migration of tumor cells, which is a key step in the development of cancer. The results demonstrated that the scratch width in RAB38 shRNA-transfected PANC-1 and BxPC-3 cells was significantly bigger, suggesting reduced migration (Fig. 4A). In addition, the possible effect of RAB38 knockdown on regulating the invasive capacity of cancer cells was detected by a Transwell invasion assay. The data indicated that the invasive capacity of RAB38-silenced PANC-1 and BxPC-3 cells was markedly 

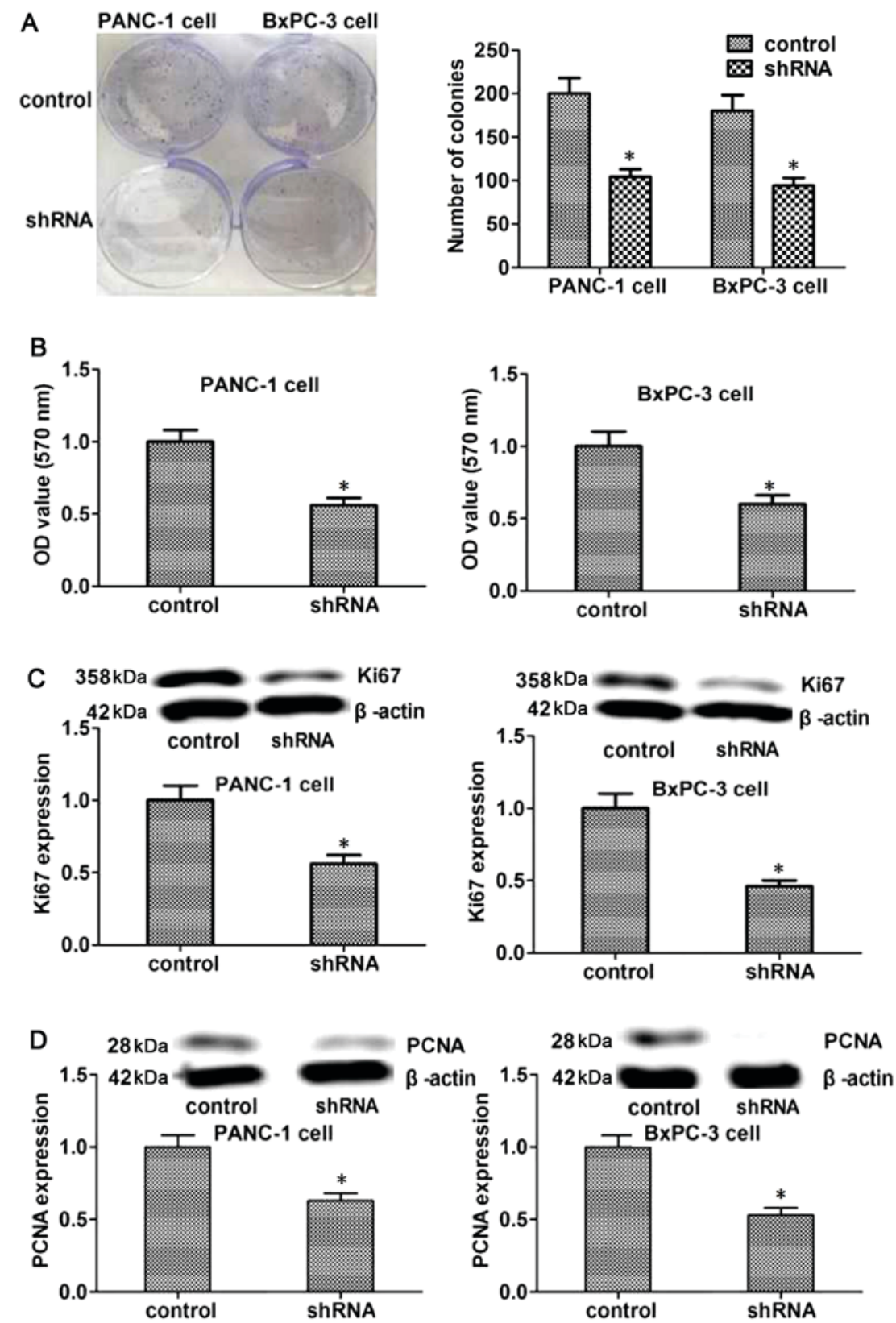

Figure 3. Effects of RAB38 silencing on the proliferation ability of PANC-1 and BxPC-3 cells. (A) Colony formation assay, indicating decreased colonies in the RAB38 shRNA-transfected group compared with the control group in vitro. (B) Cell viability in the RAB38 shRNA and control groups was analyzed using an MTT assay. Decreased OD value was detected in the RAB38 shRNA group as compared with the control group in vitro. The expression levels of the proliferation-associated proteins (C) Ki67 and (D) PCNA in PANC-1 and BxPC-3 cells were detected by western blot analysis. Data are reported as the mean \pm standard deviation $(\mathrm{n}=3)$. "P<0.05 vs. control group. shRNA, small hairpin RNA; RAB38, Ras-related GTP-binding protein 38; OD, optical density; PCNA, proliferating cell nuclear antigen.

decreased compared with that of the control cells after $48 \mathrm{~h}$ of culture (Fig. 4B).

Furthermore, to explore the mechanism underlying the effect of RAB38 silencing on the migration and invasion of cancer cells, the expression levels of the proteins that reflect invasion and metastasis, such as MMP2 and MMP9, were measured. The results suggested that the expression levels of MMP2 and MMP9 decreased significantly in the RAB38 shRNA-transfected group compared with the control group (Fig. 4C and D). These results suggested that RAB38 silencing reduced the invasive capacity of cancer cells by regulating the levels of associated proteins, including MMP2 and MMP9.
RAB38 silencing suppresses the growth of PANC-1 cancer cells in vivo. To further confirm that RAB38 silencing was able to suppress the proliferation, migration and invasion of PANC-1 cancer cells, the influence of RAB38 silencing on the growth of PANC-1 cancer cells was also detected in vivo. Nude mice were inoculated with RAB38-silenced PANC-1 cancer cells in the experimental group and with normal PANC-1 cancer cells in the control group, and the tumor growth was monitored for 3 weeks. The results demonstrated that RAB38 silencing significantly inhibited the growth of tumor cells compared with the control group (Fig. 5A). Furthermore, RAB38 expression in the tumors of these mice was detected by western blot analysis, and the results revealed reduced RAB38 protein 
A

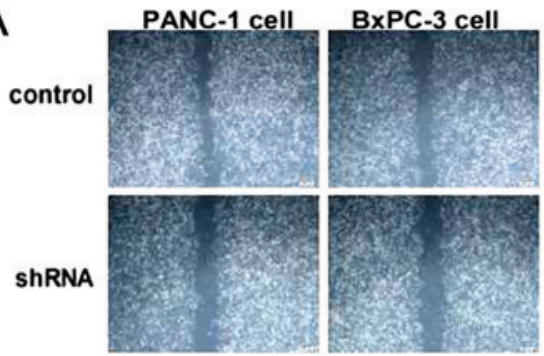

B
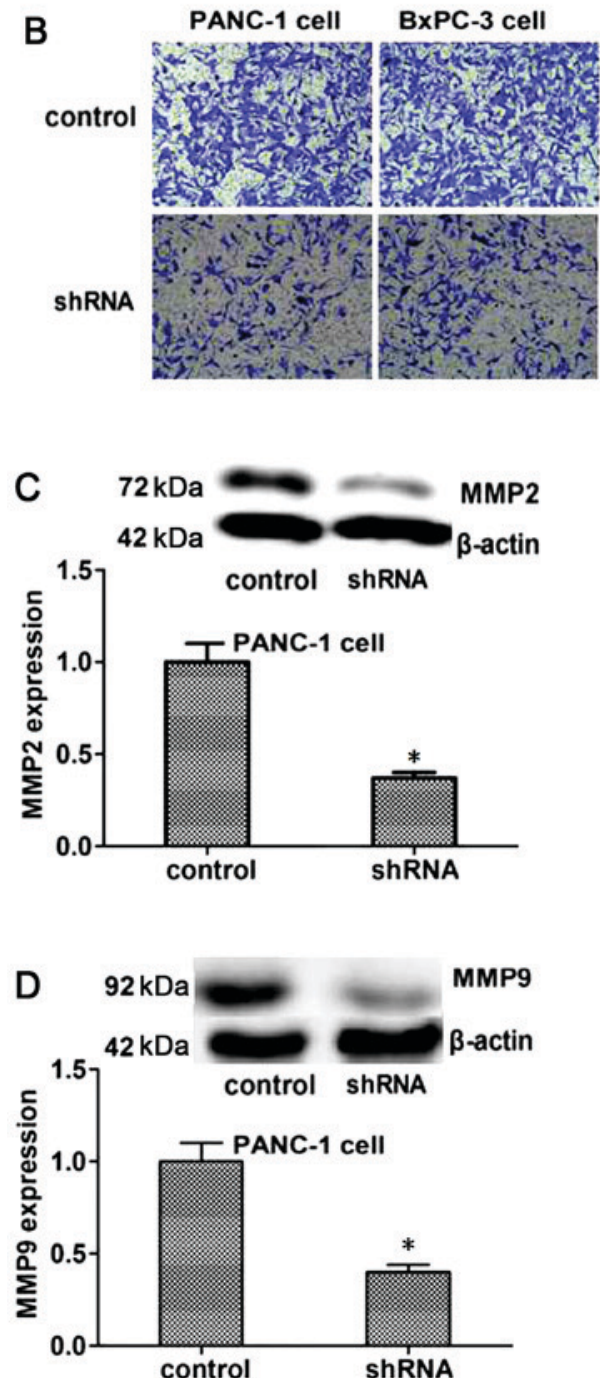
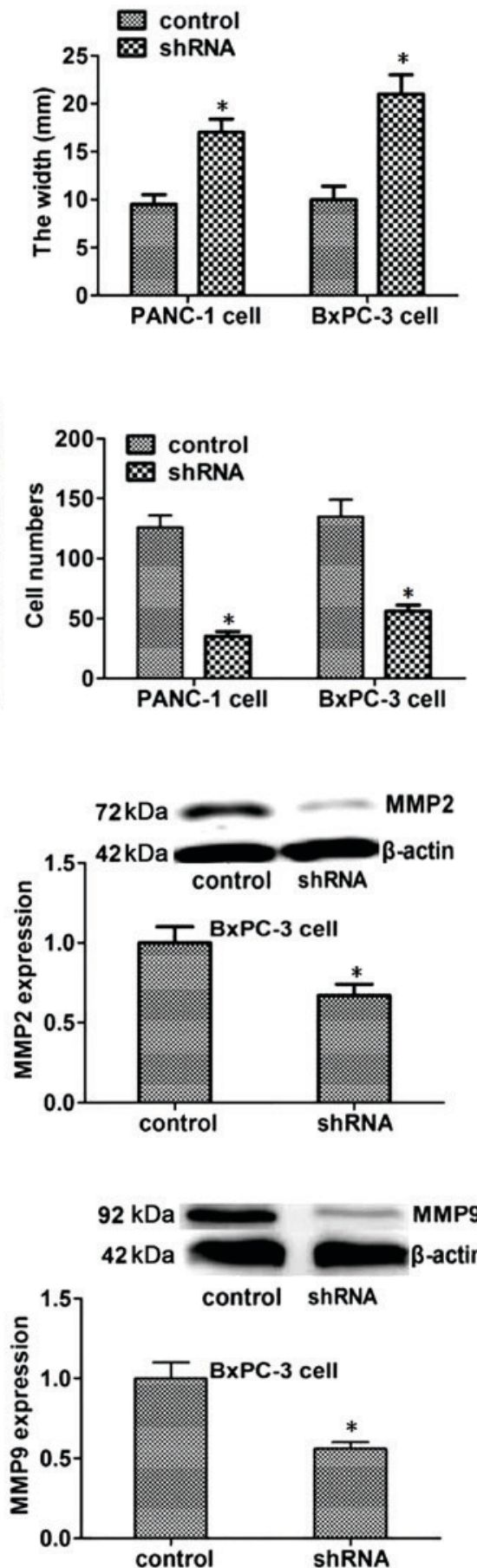

Figure 4. Influence of RAB38 on the migration and invasion of PANC-1 and BxPC-3 cells. (A) Scratch migration assay, indicating significantly a larger scratch width in the shRNA group as compared with that in the control group at $48 \mathrm{~h}$. Magnification, x200. (B) Transwell invasion assays were performed to analyze PANC-1 and BxPC-3 cells transfected with RAB38 shRNA and control shRNA. Cells were examined by light microscopy, and the cell numbers were determined in five different fields-of-view for each condition in triplicate. Magnification, $\mathrm{x} 400$. The expression levels of the metastasis-associated proteins (C) MMP2 and (D) MMP9 were detected by western blot analysis in the shRNA and control groups. Data are reported as the mean \pm standard deviation (n=3). ${ }^{*} \mathrm{P}<0.05$ vs. control group. shRNA, small hairpin RNA; RAB38, Ras-related GTP-binding protein 38; MMP, matrix metalloproteinase.

levels as a result of knockdown by shRNA ( $\mathrm{P}<0.05$, Fig. 5B). Besides, PANC-1 cells in the two groups were also injected into the tail vein of mice to observe the differences in lung metastasis. The results suggested that metastatic tumors in the RAB38 shRNA group were evidently smaller in comparison with those in the control group $(\mathrm{P}<0.05$, Fig. $5 \mathrm{C})$. These results confirmed the inhibitory effect of RAB38 shRNA on tumor growth in vivo.

\section{Discussion}

Pancreatic cancer is a highly invasive malignancy with resistance to the majority of chemotherapy strategies and no effective approaches for early diagnosis due to the atypical symptoms or signs in the initial stages of the disease in most patients (26-28). Although great efforts have been made to treat pancreatic cancer in the past decades, the outcome remains 


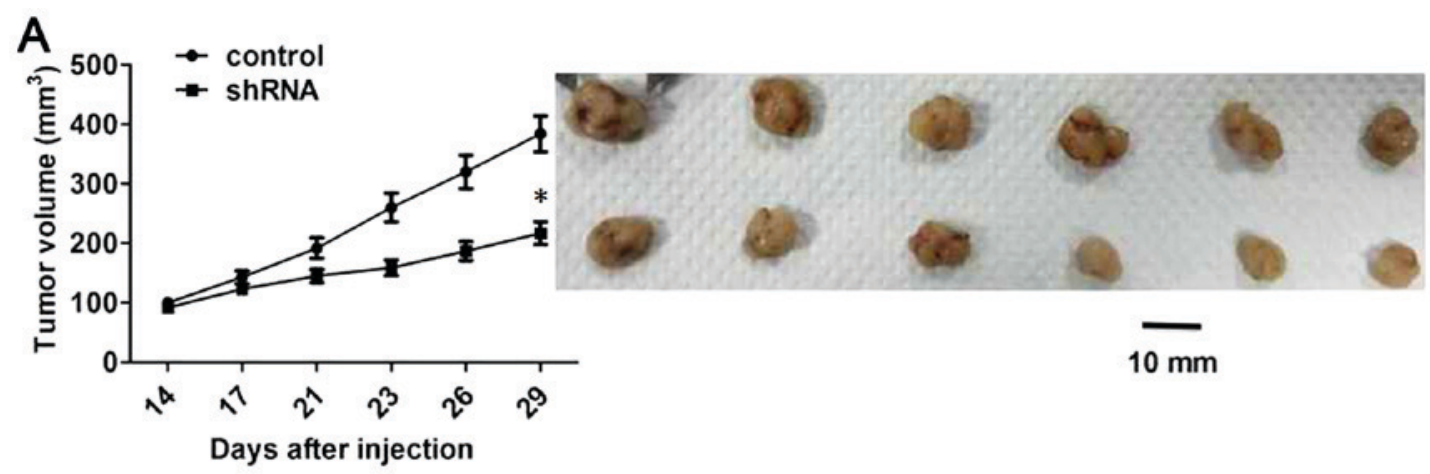

B
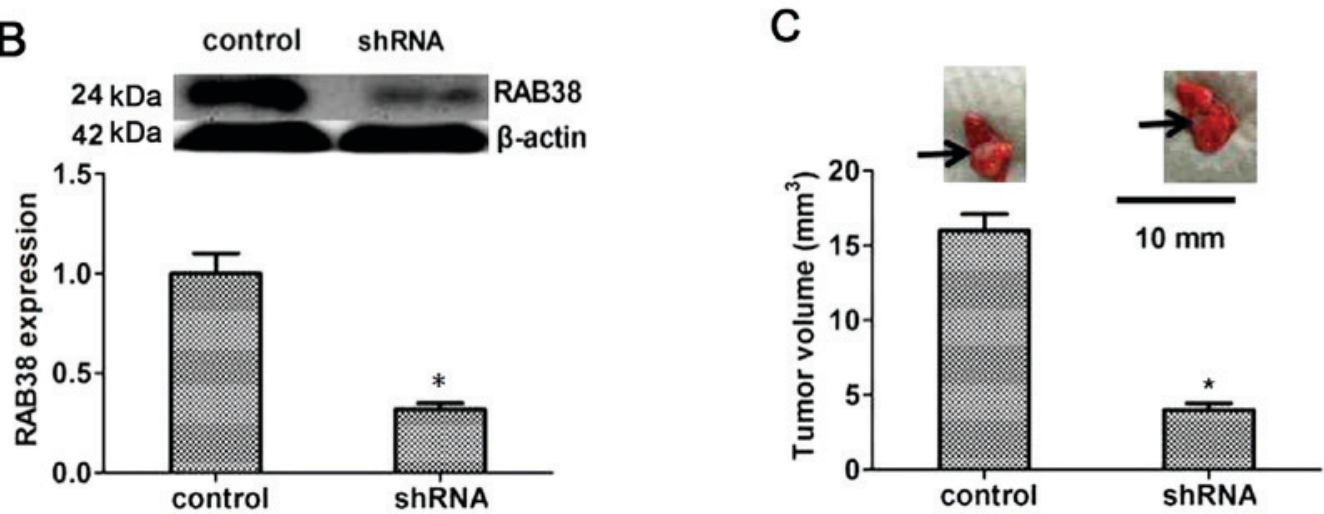

Figure 5. Effects of RAB38 silencing on the growth of PANC-1 xenograft tumors in vivo. (A) Tumor volume in the control and shRNA groups of mice. After 29 days of treatment, the tumors volume in the RAB38 shRNA group was significantly smaller compared with that in the control group. (B) Western blot analysis results of RAB38 expression in the two different groups. RAB38 expression was decreased in mice injected with RAB38 shRNA-transfected PCNA-1 cells to induce tumor xenograft. (C) Metastatic tumor volumes of mice in different groups. After 28 days of treatment, the tumor volume in the RAB38 shRNA group was smaller compared with that in the control group. " $\mathrm{P}<0.05$ vs. control group. shRNA, small hairpin RNA; RAB38, Ras-related GTP-binding protein 38.

poor. Thus, it is necessary to identify potential biomarkers and therapeutic targets for diagnosis and treatment of pancreatic cancer.

To the best of our knowledge, the present study is the first to investigate RAB38 protein expression, as well as its prognostic value, in pancreatic cancer. RAB38 belongs to the RAB superfamily and is implicated in the biogenesis of melanosomes, which helps in the synthesis, storage and transport of melanin pigments $(16,29)$. Mutation of RAB38 is associated with platelet storage pool disease $(11,30)$, and RAB38 is overexpressed at the mRNA level in melanoma cancer $(21,31,32)$ and glioma (17). It has been demonstrated that a tendency of increased RAB38 expression was observed in high grade glioma at the mRNA and protein levels, and glioma patients with higher expression of RAB38 displayed a markedly worse prognosis (17).

It is known that tumor grade progression and survival rate are vital for the clinical assessment $(33,34)$. In the current study, the expression of RAB38 was higher in pancreatic cancer with high grade as compared with that in low-grade tumors (Fig. 1), which is similar to the observations reported in the study by Wang and Jiang, where a higher RAB38 expression was more prevalent in high-grade than low-grade gliomas (17). Furthermore, the present study identified that RAB38 expression was associated with pTNM stage, tumor grade and vascular invasion; however, unlike for pTNM stage or vascular invasion, RAB38 was not an independent prognostic factor for pancreatic cancer, which was not consistent with previous studies (17-21). In addition, the current results demonstrated that pancreatic cancer patients with high expression of RAB38 had a much shorter OS and RFS, and more advanced tumor stage as compared with those in patients with low RAB38 expression.

Chemotherapeutic resistance of pancreatic cancer is the main challenge in prolonging survival (35). In the present study, knockdown of RAB38 was demonstrated to significantly inhibit the proliferation, migration and invasion abilities of pancreatic cancer cells, and reduce the expression of metastasis-associated proteins, including MMP2 and MMP9. Further investigations in animals also revealed that RAB38 silencing inhibited the growth of cancer cells. Therefore, it is presumed that RAB38 may be a new therapeutic target in pancreatic cancer. However, it is necessary to further investigate the mechanisms of RAB38 in pancreatic cancer biology in future studies. Owing to the interaction of the different signaling pathways, the upstream and downstream genes and proteins of RAB38 in pancreatic cancer, which are directly associated with RAB38 in the signaling pathway, should be identified in further studies.

In conclusion, the present study demonstrated high expression of RAB38 protein in pancreatic cancer samples, as detected by IHC assay. Prognostic analysis confirmed that high expression of RAB38 indicates a shorter survival time in pancreatic cancer. Furthermore, the current investigation provided an insight into the molecular mechanisms of RAB38 that are involved in its proliferation and metastatic potential. Therefore, RAB38 may be a novel biomarker for pancreatic cancer. 


\section{Acknowledgements}

Not applicable.

\section{Funding}

This study was funded by the Tianjin Health Bureau Science and Technology Fund (grant no. 2015KZ098).

\section{Availability of data and materials}

All data generated or analyzed during this study are included in this published article.

\section{Authors' contributions}

BYL and LJH conceived and designed the experiments. BYL, XLZ, HL and BL performed the experiments. XLZ, HL and $\mathrm{BL}$ assisted in obtaining the reagents, materials and analytical tools. All authors wrote and approved the manuscript.

\section{Ethics approval and consent to participate}

All experimental procedures involving human participants were performed in accordance with the ethical standards of the institutional and/or national research committee, and the 1964 Helsinki Declaration and its later amendments or comparable ethical standards. Informed consent was obtained from all individual participants included in the study.

\section{Patient consent for publication}

Not applicable.

\section{Competing interests}

The authors declare that they have no competing interests.

\section{References}

1. Liggett T, Melnikov A, Yi QL, Replogle C, Brand R, Kaul K, Talamonti M, Abrams RA and Levenson V: Differential methylation of cell-free circulating DNA among patients with pancreatic cancer versus chronic pancreatitis. Cancer 116: 1674-1680, 2010.

2. Kahlert C, Weber H, Mogler C, Bergmann F, Schirmacher P, Kenngott HG, Matterne U, Mollberg N, Rahbari NN, Hinz U, et al: Increased expression of ALCAM/CD166 in pancreatic cancer is an independent prognostic marker for poor survival and early tumour relapse. Br J Cancer 101: 457-464, 2009.

3. Arcidiacono PG, Bhutani MS and Giovannini M: EURO-EUS 2003: Pancreatic tumor: Impact of endoscopic ultrasonography on diagnosis, staging and treatment. Cancer Biol Ther 3: 477-481, 2004

4. Mcgough $\mathrm{N}$ and Cummings JH: Coeliac disease: A diverse clinical syndrome caused by intolerance of wheat, barley and rye. Proc Nut Soc 64: 434-450, 2005.

5. Garcea G, Dennison AR, Pattenden CJ, Neal CP, Sutton CD and Berry DP: Survival following curative resection for pancreatic ductal adenocarcinoma. A systematic review of the literature. JOP 9: 99-132, 2008.

6. Martin RC II, Kwon D, Chalikonda S, Sellers M, Kotz E, Scoggins C, McMasters KM and Watkins K: Treatment of 200 locally advanced (stage III) pancreatic adenocarcinoma patients with irreversible electroporation: Safety and efficacy. Ann Surg 262: 486-494, 2015.
7. Yu J and Chen Q: Antitumor activities of rauwolfia vomitoria extract and potentiation of gemcitabine effects against pancreatic cancer. Integr Cancer Ther 13: 217-225, 2014.

8. Mccarroll J, Teo J, Boyer C, Goldstein D, Kavallaris M and Phillips PA: Potential applications of nanotechnology for the diagnosis and treatment of pancreatic cancer. Front Physiol 5: 2, 2014.

9. Wolfgang CL, Herman JM, Laheru DA, Klein AP, Erdek MA, Fishman EK and Hruban RH: Recent progress in pancreatic cancer. CA Cancer J Clini 63: 318-348, 2013.

10. Hussain SP: Pancreatic cancer: Current progress and future challenges. Int J Biol Sci 12: 270-272, 2016.

11. Wasmeier C, Romao M, Plowright L, Bennett DC, Raposo G and Seabra MC: Rab38 and Rab32 control post-Golgi trafficking of melanogenic enzymes. J Cell Biol 175: 271-281, 2006.

12. Chan AM and Weber T: A putative link between exocytosis and tumor development. Cancer Cell 2: 427-428, 2002.

13. Hutagalung AH and Novick PJ: Role of Rab GTPases in membrane traffic and cell physiology. Physiol Rev 91: 119-149, 2011.

14. Grosshans BL, Ortiz D and Novick P: Rabs and their effectors: Achieving specificity in membrane traffic. Proc Nati Acad Sci USA 103: 11821-11821, 2006.

15. Osanai K, Higuchi J, Oikawa R, Kobayashi M, Tsuchihara K, Iguchi M, Huang J, Voelker DR and Toga H: Altered lung surfactant system in a Rab38-deficient rat model of Hermansky-Pudlak syndrome. Am J Physiol Lung Cell Mol Physiol 298: 243-251, 2010.

16. Osanai K, Takahashi K, Nakamura K, Takahashi M, Ishigaki M, Sakuma T, Toga H, Suzuki T and Voelker DR: Expression and characterization of Rab38, a new member of the Rab small G protein family. Biol Chem 386: 143-153, 2005.

17. Wang $\mathrm{H}$ and Jiang $\mathrm{C}$ : Rab38 confers a poor prognosis, associated with malignant progression and subtype preference in glioma. Oncol Rep 30: 2350-2356, 2013.

18. Bultema JJ and Di PSM: Cell type-specific Rab32 and Rab38 cooperate with the ubiquitous lysosome biogenesis machinery to synthesize specialized lysosome-related organelles. Small Gtpases 4: 16-21, 2013.

19. Lopes VS, Wasmeier C, Seabra MC and Futter CE: Melanosome maturation defect in Rab38-deficient retinal pigment epithelium results in instability of immature melanosomes during transient melanogenesis. Mol Biol Cell 18: 3914-3927, 2007.

20. Jäger D, Stockert E, Jäger E, Güre AO, Scanlan MJ, Knuth A, Old LJ and Chen YT: Serological cloning of a melanocyte rab guanosine 5'-triphosphate-binding protein and a chromosome condensation protein from a melanoma complementary DNA library. Cancer Res 60: 3584-3591, 2000.

21. Abdelmonsef AH, Dulapalli R, Dasari T, Padmarao LS, Mukkera T and Vuruputuri U: Structure based drug discovery of Rab38 protein-identification of antagonists as cancer drug candidates. Comb Chem High Throughput Screen 19: 875-892, 2016.

22. Na L, Tang B, Zhu ED, Li BS, Zhuang Y, Yu S, Lu DS, Zou QM, Xiao B and Mao XH: Increased miR-222 in H. pylori-associated gastric cancer correlated with tumor progression by promoting cancer cell proliferation and targeting RECK. FEBS Lett 586: 722-728, 2012.

23. Moffat J, Grueneberg DA, Yang X, Kim SY, Kloepfer AM, Hinkle G, Piqani B, Eisenhaure TM, Luo B, Grenier JK, et al: A lentiviral RNAi library for human and mouse genes applied to an arrayed viral high-content screen. Cell 124: 1283-1298, 2006.

24. Zhu E, Wang X, Zheng B, Wang Q, Hao J, Chen S, Zhao Q, Zhao L, Wu Z and Yin Z: miR-20b suppresses Th17 differentiation and the pathogenesis of experimental autoimmune encephalomyelitis by targeting RORgammat and STAT3. J Immunol 192: 5599-5609, 2014.

25. Livak KJ, and Schmittgen TD: Analysis of relative gene expression data using real-time quantitative PCR and the $2^{-\Delta \Delta C T}$ method. Methods 25: 402-408, 2001.

26. Han S, Jin G, Wang L, Li M, He C, Guo X and Zhu Q: The role of PAM4 in the management of pancreatic cancer: Diagnosis, radioimmunodetection, and radioimmunotherapy. J Immunol Res 2014: 268479, 2014

27. Buscarini E, Pezzilli R, Cannizzaro R, De Angelis C, Gion M, Morana G, Zamboni G, Arcidiacono P, Balzano G, Barresi L, et al: Italian consensus guidelines for the diagnostic work-up and follow-up of cystic pancreatic neoplasms. Dig Liver Dis 46: 479-493, 2014.

28. Herrmann P, Huber S, Hesler CV, Tischer A, Luckner M, Bruns C and Heeschen C: Identification and characterization of highly metastatic and therapy resistant tumor stem cells in pancreatic cancer. Cancer Res 67: 1292-1292, 2007. 
29. Osanai K, Iguchi M, Takahashi K, Nambu Y, Sakuma T, Toga H, Ohya N, Shimizu H, Fisher JH and Voelker DR: Expression and localization of a novel Rab small $\mathrm{G}$ protein (Rab38) in the rat lung. Am J Pathol 158: 1665-1675, 2001.

30. Ninkovic I, White JG, Rangelfilho A and Datta YH: The role of Rab38 in platelet dense granule defects. J Thromb Haemost 6 : 2143-2151, 2008

31. Walton SM, Gerlinger M, de la Rosa O, Nuber N, Knights A, Gati A, Laumer M, Strauss L, Exner C, Schäfer N, et al: Spontaneous CD8 T cell responses against the melanocyte differentiation antigen RAB38/NY-MEL-1 in melanoma patients. J Immunol 177: 8212-8218, 2006.

32. Abdelmonsef AH, Dulapalli R, Dasari T, Padmarao LS, Mukkera T and Vuruputuri U: Identification of novel antagonists for Rab38 protein by homology modeling and virtual screening. Comb Chem High Throughput Screen 19: 875-892, 2016.
33. He AR and Goldenberg AS: Treating hepatocellular carcinoma progression following first-line sorafenib: Therapeutic options and clinical observations. Therap Adv Gastroenterol 6: 447-458, 2013.

34. Hicks J, Krasnitz A, Lakshmi B, Navin NE, Riggs M, Leibu E, Esposito D, Alexander J, Troge J, Grubor V, et al: Novel patterns of genome rearrangement and their association with survival in breast cancer. Genome Res 16: 1465-1479, 2006.

35. Borowa-Mazgaj B: Pancreatic cancer-mechanisms of chemoresistance. Postepy Hig Med Dosw (Online) 70: 169-179, 2016 (In Polish).

(i) $($ ) 9 This work is licensed under a Creative Commons Attribution-NonCommercial-NoDerivatives 4.0 International (CC BY-NC-ND 4.0) License. 